\title{
Akebono Observations of the Polar Wind and Suprathermal Auroral Ions: An Overview
}

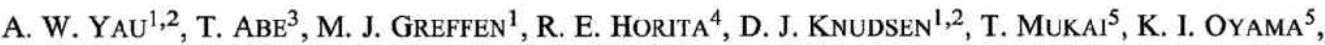 \\ W. K. Peterson ${ }^{6}$, E. Sagawa ${ }^{7}$, S. Watanabe ${ }^{8}$, and B. A. Whalen ${ }^{2}$ \\ ${ }^{1}$ Department of Physics and Astronomy, University of Calgary, Calgary, Alberta, Canada T2N1N4 \\ ${ }^{2}$ Herzberg Institute of Astrophysics, National Research Council Canada, Ottawa, Ontario, Canada KIA0R6 \\ ${ }^{3}$ College of Science and Engineering, Aoyama Gakuin University, Tokyo 157, Japan \\ ${ }^{4}$ Department of Physics and Astronomy, University of Victoria, Victoria, British Columbia, Canada V8W2Y2 \\ ${ }^{5}$ Institute of Space and Astronautical Science, 3-1-1 Yoshinodai, Sagamihara, Kanagawa 229, Japan \\ ${ }^{6}$ Lockheed Palo Alto Research Laboratory, Palo Alto, California 94304, U.S.A. \\ ${ }^{7}$ Hiraiso Solar Terrestrial Research Center, Communications Research Laboratory, Ibaraki 311, Japan \\ ${ }^{8}$ Department of Astronomy and Geophysics, Tohoku University, Sendai 980, Japan
}

(Received December 8, 1994; Revised November 8, 1995; Accepted December 13, 1995)

\begin{abstract}
We present an overview of direct ion and electron observations of the polar wind and suprathermal auroral ions from the plasma instruments on Akebono. In the polar wind, the observed $\mathrm{H}^{+}$ion reaches a velocity of $1 \mathrm{~km} / \mathrm{s}$ at $2000 \mathrm{~km}$ altitude, as does $\mathrm{He}^{+}$ion near $3000 \mathrm{~km}$ and $\mathrm{O}^{+}$ion near $6000 \mathrm{~km}$. At high altitudes, the $\mathrm{O}^{+}$ion constitutes a significant component of the polar wind flow contrary to most polar wind model predictions. At $2000-4000 \mathrm{~km}$, the $\mathrm{H}^{+}$ion velocity in the polar wind is strongly correlated with the ambient electron temperature. The electron temperature (averaged thermal energy) in the upward magnetic field direction is a factor of 1.5-2 higher than that in the downward and field-perpendicular directions. This results in an upward heat flux which is comparable in magnitude to the heat flux carried by energetic $(>10-\mathrm{eV})$ photoelectrons. The observed electron temperature anisotropy and correlation with ion velocity are consistent with the polar wind being driven by a large ambipolar electric field resulting from the presence of escaping atmospheric photoelectrons (required to maintain quasineutrality along the field line). At auroral latitudes, significant fluxes of "minor ions" are frequently observed, particularly atomic $\mathrm{N}^{+}$and $\mathrm{O}^{++}$ions and molecular $\mathrm{NO}^{+}, \mathrm{N}_{2}{ }^{+}$, and $\mathrm{O}_{2}{ }^{+}$ions. The occurrence of molecular ions at high altitude $(>3000 \mathrm{~km})$ during extended periods of auroral activity points to their fast energization at the $F$-region and topside ionosphere. In the $3000-6000 \mathrm{~km}$ altitude region, transverse ion energization occurs frequently both on the dayside and the nightside. Different ion species are energized in the perpendicular direction to tens and at times hundreds of $\mathrm{eV}$ over a narrow spatial extent, and appear as "ion conics" at higher altitudes as they spiral up the field lines. In the $3000-9000 \mathrm{~km}$ altitude region, the average energy of the observed ion conics in the dayside auroral zone increases with altitude.
\end{abstract}

\section{Introduction}

Outflowing ions from the polar ionosphere are an important source of energetic ions in the magnetosphere (Chappell, 1988) and they fall into two catagories: the polar wind, and the suprathermal ion flows (Yau and Lockwood, 1988). In this paper, we present an overview of direct ion and electron observations of both catagories of outflowing ions from the plasma instruments on the polar-orbiting Akebono satellite.

The term "classical" polar wind refers to the ambipolar outflow of thermal ionospheric plasma along "open" magnetic field lines in the polar ionosphere, due to the plasma pressure gradient along the field lines. The concept of light ion escape from the polar ionosphere was first proposed by Dessler and Michel (1966) in terms of an evaporative process of thermal ions, and by Nishida (1966) in terms of plasma diffusion due to plasma pressure gradient along open field lines in connection with the formation of the plasmapause. Several theoretical models of the polar wind exist in the literature. These include timeindependent hydrodynamic (Banks and Holzer, 1968; Marubashi, 1970), hydromagnetic (Holzer et al., 
1971), kinetic (Lemaire, 1972), and generalized-transport-equations based models (Schunk and Watkins, 1981; Mitchell and Palmadesso, 1983); and time-dependent hydrodynamic (Gombosi and Nagy, 1989; Schunk and Sojka, 1989) and semi-kinetic models (Ho et al., 1992).

The $F$-region and topside polar ionosphere is composed primarily of three ion mass species: $\mathrm{H}^{+}, \mathrm{He}^{+}$, and $\mathrm{O}^{+}$. The $\mathrm{He}^{+}$and $\mathrm{O}^{+}$ions originate from the photoionization of $\mathrm{He}, \mathrm{O}$, and $\mathrm{O}_{2}$ in the $F$-region. The $\mathrm{H}^{+}$ ions result from the accidentally resonant charge exchange reaction between $\mathrm{O}^{+}$ions and neutral atomic hydrogen $(\mathrm{H})$ in the topside ionosphere. The classical polar wind theory predicted the upward flow of the light $\mathrm{H}^{+}$and $\mathrm{He}^{+}$ions relative to the heavy $\mathrm{O}^{+}$ion under typical ionospheric conditions. This prediction was confirmed by ion composition observations at low altitudes, where the relative arrival angles of the respective ion species in the polar region were used to infer the presence of upward $\mathrm{H}^{+}$and $\mathrm{He}^{+}$ion flows on both ISIS-2 at $1400 \mathrm{~km}$ (Hoffman and Dodson, 1980) and DE-1 up to $4000 \mathrm{~km}$ (Chandler et al., 1991).

In many polar wind models, the $\mathrm{H}^{+}$and $\mathrm{He}^{+}$ions are predicted to reach supersonic speeds at high altitudes (above $\sim 1500 \mathrm{~km}$ for $\mathrm{H}^{+}$; see for example Schunk and Watkins, 1981). In contrast, the $\mathrm{O}^{+}$ion is predicted or assumed to remain essentially stationary at all altitudes, except under elevated temperature conditions (Barakat and Schunk, 1983) or in the presence of hot magnetospheric electrons (Ho et al., 1992) or significant ion heating (Gombosi et al., 1985). Observationally, supersonic $\mathrm{H}^{+}$and $\mathrm{He}^{+}$polar wind ions were observed in the nightside polar cap near 2- $\mathrm{R}_{\mathrm{E}}$ altitude during a large auroral substorm on DE-1 (Nagai et al., 1984). The possible presence of oxygen in the high-altitude polar wind flow was an open question prior to Akebono.

Previous observations of the different types of suprathermal outflowing ions in the auroral ionosphere were reviewed in Yau and Lockwood (1988). These include upwelling ions, upflowing polar-cap ions, transversely energized ions, and auroral ion beams and conics. However, none of the previous observations contains a complete characterization of the ion population (thermal and suprathermal) in and near the source region of energization. Also, mass composition information was generally absent or limited.

The Akebono satellite was launched on February 21, 1989, and placed in an elliptical, polar orbit at $75^{\circ}$ inclination, with an initial apogee of $10,500 \mathrm{~km}$, a perigee of $275 \mathrm{~km}$, an orbital period of $212 \mathrm{~min}$., and an apogee latitude precession period of approximately 19 months (Tsuruda and Oya, 1991).

The SMS instrument on Akebono is a radio frequency $(R F)$ type ion mass spectrometer, and it measures the mass-per-charge $(M / Q)$, energy-per-charge $(E / Q)$, and angular distributions of positive ions in the 0.9-67 amu/q range (Whalen et al., 1990). Both in the thermal (0.1-20 eV/q) and the suprathermal (20-4000 eV/q) energy ranges, it is capable of routinely and simultaneously measuring both major and minor ion species. Its relative mass response function is independent of ion mass species, and its mass line profile falls off sharply (exponentially) on both sides of the mass peak, making it possible to resolve minor ion species from nearby major species (Yau et al., 1991). It has three selectable entrance apertures, which span a range of $\sim 10^{5}$ in geometric factor, and give it a dynamic range of $\sim 10^{9}$ in measured thermal-energy ion flux. In its mass scan modes, SMS measures 864 -point mass spectra every spacecraft spin. In its fast scan modes, it samples selected ion species only, and typically measures 32 8-point energy (or retarding potential) spectra per spin for each of 4 selected species. The measured distributions of the respective species are used to derive the various plasma parameters, including the spacecraft potential, the convection velocity, and the parallel velocity, temperature and density of individual species (Watanabe et al., 1992).

The TED instrument consists of two planar probes which are mounted perpendicular to each other and view radially out of the spin plane (Abe et al., 1990). In one of its operation modes, each sensor completes four 0.5-s (two upward and two downward) voltage sweeps in the 0-5 V range in each spin. In each sweep, the second harmonic component of the incident probe current is measured as a function of the probe voltage. The measured current data in each sweep are used to derive the electron temperature in the sensor direction (Abe et al., 1990), resulting in 8 independent temperature estimates per spin. In the case of an isotropic Maxwellian distribution, the measured currents may also be used to estimate the electron density.

The LEP instrument has two sets of identical energy-per-charge $(E / Q)$ analyzers (Mukai et al., 1990), 
and measures ions and electrons at 64 logarithmic steps in the $\sim 0.1-16 \mathrm{keV} / \mathrm{q}$ range. Each set is composed of a nested set of quadrispherical electrostatic analyzers, 5 channel electronmultipliers for ionmeasurements, and the same for electron measurements. Together, the two sets of analyzers cover the full (or nearly full) $180^{\circ}$ pitch angle range.

\section{The Polar Wind}

On Akebono, the polar wind ions are observed at all latitudes and local times poleward of the plasmasphere, and generally have energies below $10 \mathrm{eV}$. The suprathermal ions are predominantly observed at auroral latitudes, and generally have energies above $10 \mathrm{eV}$.

Abe et al. (1993a) presented averaged altitude profiles for the polar wind velocities of the three major ion species $\left(\mathrm{H}^{+}, \mathrm{He}^{+}\right.$, and $\left.\mathrm{O}^{+}\right)$up to the Akebono apogee $(10,000 \mathrm{~km})$. Figure 1 shows the measured profiles (a) on the dayside and (b) on the nightside. At a given altitude, the velocity is smaller for the heavier ion species, i.e., the $\mathrm{O}^{+}$velocity is smaller than the $\mathrm{He}^{+}$velocity, which is in turn smaller than the $\mathrm{H}^{+}$velocity. The velocity increases with altitude; for $\mathrm{H}^{+}$, the rate of velocity increase is largest between 2000 and 4000 $\mathrm{km}$, and is gradually smaller at higher altitudes. The $\mathrm{H}^{+}$velocity typically reaches $1 \mathrm{~km} / \mathrm{s}$ near $2000 \mathrm{~km}$, as does the $\mathrm{He}^{+}$velocity near $3000 \mathrm{~km}$ and the $\mathrm{O}^{+}$velocity near $6000 \mathrm{~km}$. At Akebono apogee $(10,000 \mathrm{~km})$, the averaged $\mathrm{H}^{+}, \mathrm{He}^{+}$and $\mathrm{O}^{+}$velocities are $\sim 12,6$, and $4 \mathrm{~km} / \mathrm{s}$, respectively, on the dayside.

The large $\mathrm{O}^{+}$velocity at high altitude is in direct contrast with theoretical predictions from many polar wind models, in which the $\mathrm{O}^{+}$ions are expected to be stationary at all altitudes under typical ionospheric conditions (e.g., Schunk and Watkins, 1981). As noted earlier, the time-dependent model of Gombosi et

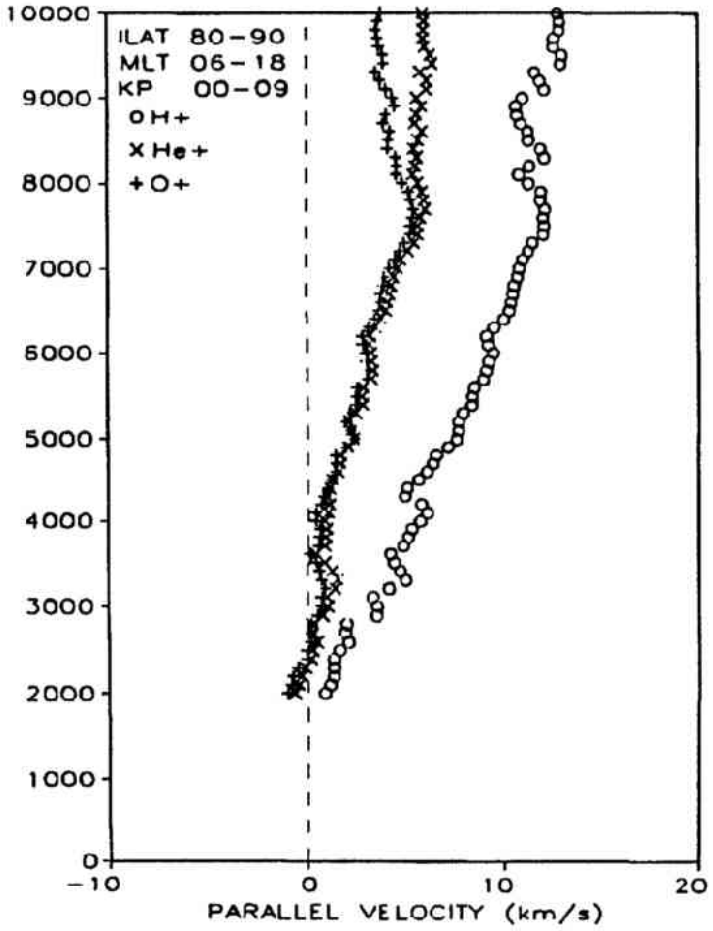

(a)

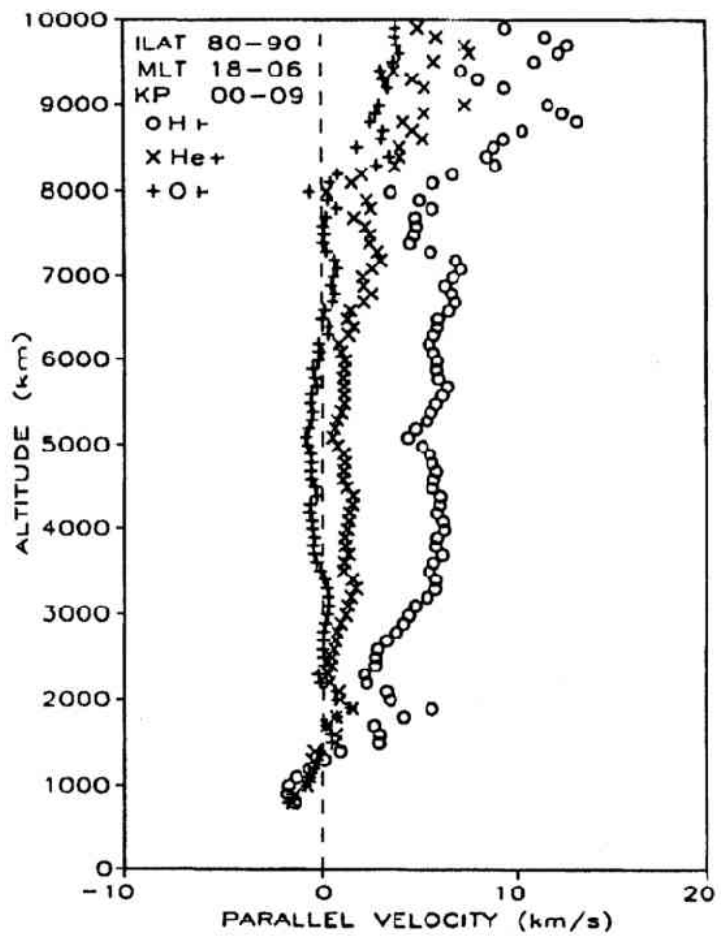

(b)

Fig. 1. Averaged Akebono SMS polar wind $\mathrm{H}^{+}, \mathrm{He}^{+}$and $\mathrm{O}^{+}$ion velocity versus altitude on (a) the dayside and (b) the nightside above $80^{\circ} \Lambda$. 
al. (1985) predicted the possibility of supersonic $\mathrm{O}^{+}$flow. Barakat and Schunk (1983) also showed the possibility of large $\mathrm{O}^{+}$velocity at elevated electron temperatures $\left(T_{\mathrm{e}}>10^{4} \mathrm{~K}\right)$. The observed $\mathrm{H}^{+}$velocity at low altitude (below $2000 \mathrm{~km}$ ) is comparable to the assumed values in theoretical models for subsonic flows, and is much smaller than typical values in models of supersonic flows.

$\mathrm{O}^{+}$flow of larger velocities $(\sim 10 \mathrm{~km} / \mathrm{s})$ was observed on DE-1 above $2 \mathrm{R}_{\mathrm{E}}$ altitude. It was interpreted previously as ions originating from the cleft ion fountain (Pollock et al., 1990), and more recently as centrifugally accelerated polar wind ions (Horwitz et al., 1994). Lockwood et al. (1985) showed that upwelling $\mathrm{O}^{+}$ions, from which the cleft ion fountain originates, occur exclusively in the morning sector of the auroral oval. In comparison, the observed $\mathrm{O}^{+}$polar wind flow on Akebono peaks in the afternoon sector regardless of the IMF condition and the ionospheric convection pattern (Abe et al., 1993a, 1995). Also, the occurrence frequency of upwelling ions is highest in the summer and is zero in the winter. In contrast, $\mathrm{O}^{+}$flow was regularly observed on Akebono in the winter months. Therefore, the observed flows on Akebono appear to be distinct from the cleft ion fountain. From model simulation, Ho et al. (1994) found that centrifugal acceleration due to the convection electric field can increase the $\mathrm{O}^{+}$flow velocity by several folds at Akebono altitude. To ascertain its possible importance, we plan to study the threedimensional velocity of the observed polar wind ions as it becomes available, by combining the electric field and ion measurements on Akebono.

Figure 1 shows that for all three ion species, the velocity exhibits a day-to-night asymmetry. At a given altitude, the velocity is generally higher on the dayside. The dayside-to-nightside ratio of the $\mathrm{H}^{+}$ velocity is as large as 2 near Akebono apogee.

In a given orbit pass, the measured velocity generally increases with altitude in the $2000-4000 \mathrm{~km}$ altitude region, from about $1 \mathrm{~km} / \mathrm{s}$ at $2000 \mathrm{~km}$ altitude to about $6 \mathrm{~km} / \mathrm{s}$ at $4000 \mathrm{~km}$ altitude. However, the altitude profile sometimes exhibits large variations from a smooth, monotonic trend. Such variations are attributed to latitudinal or local time variations in ionospheric conditions in localized regions of the polar cap.

The measured ion velocity of the $\mathrm{H}^{+}$polar wind at a given altitude appears to be more variable during active times than it is at quiet times. For example, the variability (standard deviation) of the velocity is as much as $50 \%$ of the mean velocity at apogee during active times. However, the average velocity at quiet times $\left(K_{p} \leq 3\right)$ is very similar to that at active times $\left(K_{p}>4\right.$; Abe et al., 1993b).

The velocity at a given altitude is found to correlate with the ambient electron temperature (Abe $e t$ al., 1993b). Figure 2 presents scatter plots of the $\mathrm{H}^{+}$velocity versus the electron temperature in three different altitude intervals centered at 2000,2500 , and $3000 \mathrm{~km}$, respectively, as well as the linear least squares fit to the data. At all three altitudes, the ion velocity increases with the electron temperature. The correlation is strongest - the relative increase in ion velocity with electron temperature is largest - at high altitude. For an electron temperature change from $4000^{\circ} \mathrm{K}$ to $7000^{\circ} \mathrm{K}$, the velocity increase was about 50 percent (from $1 \mathrm{~km} / \mathrm{s}$ to $1.5 \mathrm{~km} / \mathrm{s}$ ) at $2000 \mathrm{~km}$, and a factor of 3 at $3000 \mathrm{~km}$. This presumably reflects the cumulative effect of ion acceleration due to the ambipolar electric field along the field line, and the direct relationship between the local magnitude of the ion acceleration and that of the ambipolar electric field responsible for the acceleration.

At high altitudes $(>3000 \mathrm{~km})$ in the nightside, the plasma density is frequently depleted over an extended latitudinal region. Horita et al. (1993) found such "ion depletion zones" (IDZ) poleward of the auroral zone $\left(>70^{\circ} \Lambda\right)$ on the nightside in as much as $50 \%$ of the orbit passes. Figure 3 shows the invariant latitude versus magnetic local time plots of a number of orbit passes in which IDZ was observed. Figure 3a shows the ground tracks of the orbit passes, which were fairly uniformly distributed in altitude and latitude in the $2000-10000 \mathrm{~km}$ altitude region above $60^{\circ}$ invariant on both the dayside and the nightside. Figures $3 \mathrm{~b}-\mathrm{d}$ show the portions of the orbit passes over which hydrogen, helium, and oxygen IDZ were "observed", respectively. The figure indicates that the IDZ are predominantly in the nightside and at invariant latitudes above $70^{\circ}$; there is some indication that a larger percentage of the IDZ lies within $70^{\circ}$ to $80^{\circ}$ invariant latitude. A comparison of the individual orbits in Figs. 3b, 3c, and $3 \mathrm{~d}$ shows that the patterns for $\mathrm{H}^{+}, \mathrm{He}^{+}$, and $\mathrm{O}^{+} \mathrm{IDZ}$ are very similar, and that the spatial extent of the $\mathrm{O}^{+} \mathrm{IDZ}$ is the largest 
(a)

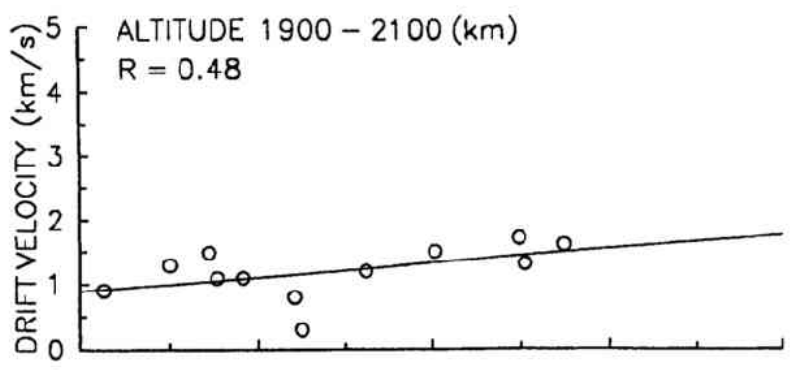

(b)

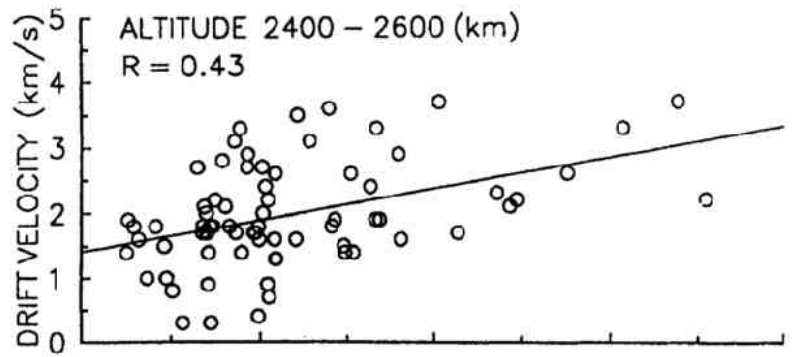

(c)

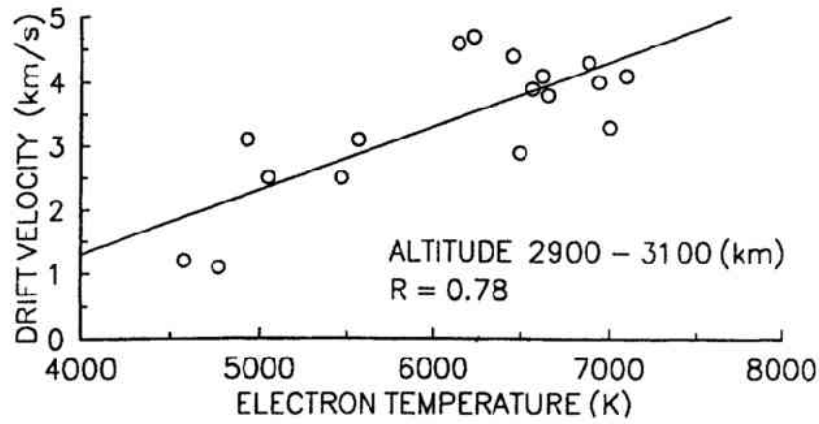

Fig. 2. Scatter plot of $\mathrm{H}^{+}$polar wind ion velocity measured by SMS versus electron temperature measured by TED on Akebono at (a) $2000 \mathrm{~km}$; (b) $2500 \mathrm{~km}$; and (c) $3000 \mathrm{~km}$.

while that of the $\mathrm{H}^{+}$IDZ is the smallest. The occurrence of the IDZ does not appear to be magnetic activity dependent, and may be indicative of regions that are devoid of both ions convecting in from other regions and locally produced ions.

On Akebono, simultaneous electron temperature measurements in the magnetic field and perpendicular directions are available from a small number of orbit passes in the polar wind region. In some of these orbit passes, measurements are also available at intermediate pitch angles. For brevity, the term temperature is used here to refer to the averaged thermal energy of a particle velocity distribution regardless of whether the distribution is Maxwellian or otherwise. The TED data in these orbit passes reveal an asymmetry in the electron velocity distribution in the field-aligned direction (Yau et al., 1995). Specifically, the measured velocity distribution in the upward magnetic field direction is characterized by a higher temperature than those in the perpendicular and the downward directions. The upward temperature is typically a factor of 1.5 to 2 higher than the perpendicular and the downward temperatures, i.e., $T_{\|, \text {up }} / T_{\|, \text {down }}$ $\sim 1.5-2.0$, and $T_{\|, \text {down }} / T_{\perp} \sim 1.0$. In other words, the upward-moving ambient electrons (those with pitch angles near $180^{\circ}$ in the northern hemisphere) are on average more energetic than their downward-moving (near $0^{\circ}$ pitch angles) and locally mirroring (near $90^{\circ}$ pitch angles) counterparts.

Figure 4 shows the measured electron temperature as a function of electron pitch angle, from a lowaltitude orbit pass through the dayside northern polar cap $\left(>80^{\circ} \Lambda, 16-20 \mathrm{MLT}\right)$ from 2478 to $2818 \mathrm{~km}$ 


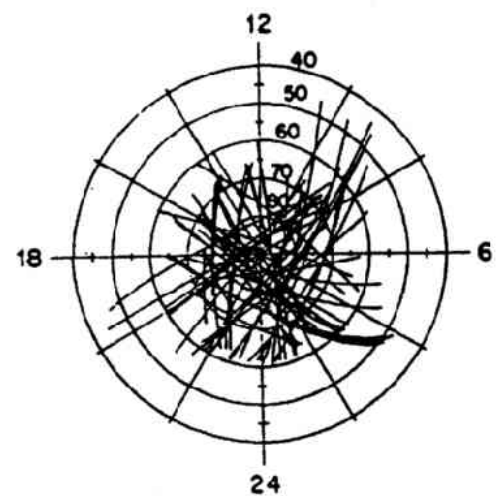

(a) TOTAL ORBitAL COVERAGE

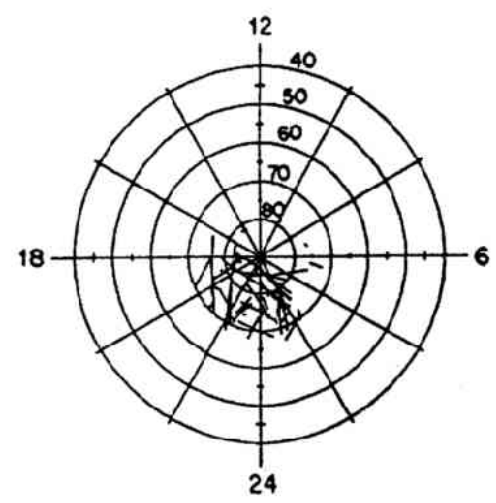

(b) $\mathrm{H}^{+} \mathrm{IDZ}$

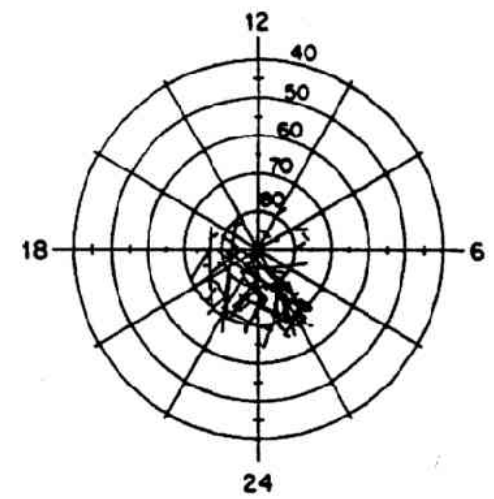

(c) $\mathrm{He}^{+} \mathrm{IOZ}$

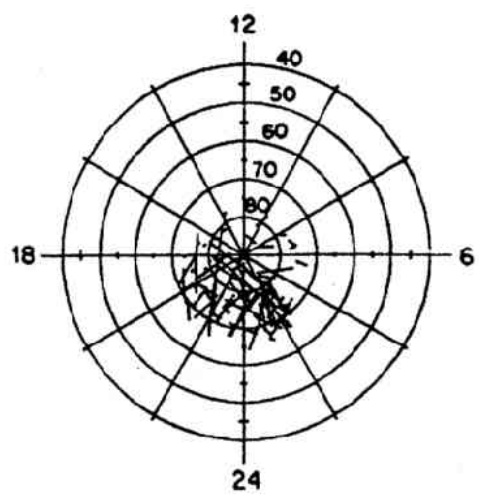

(d) $0^{+} 102$

Fig. 3. (a) Invariant latitude versus MLT plot of selected Akebono orbit passes in which ion depletion zones (IDZ) were observed; (b)-(d) portions of orbits in which the $\mathrm{H}^{+}, \mathrm{He}^{+}$, and $\mathrm{O}^{+} \mathrm{IDZ}$ were observed, respectively.

altitude. Data from both TED sensors are combined in this figure, in order to cover the full $180^{\circ}$ pitch angle range. The measured temperature near the upward magnetic field direction $\left(>150^{\circ}\right.$ pitch angle) is significantly larger than that near the downward and perpendicular directions. Also, the data from the two sensors are consistent with each other where they overlap (near $50^{\circ}$ and $140^{\circ}$ pitch angles). The higher temperatures near the upward magnetic field direction cannot be attributed to wake effects since they were measured at small ram angles, away from the spacecraft wake. Indeed, if spacecraft wake effects were present, they would be expected to increase the measured electron temperatures at the perpendicular and downward directions, which were made at larger ram angles. In other words, the actual temperatures in the downward and perpendicular directions would have been smaller than the measured values, and the actual difference between the upward and downward temperatures would have been larger than observed.

The higher electron temperature (average thermal energy) in the upward magnetic field direction relative to that in the downward direction results in an estimated heat flux of $\sim 1.0 \times 10^{-5} \mathrm{Joule} \mathrm{m}^{-2} \mathrm{~s}^{-1}$ in the upward direction at $\sim 2500 \mathrm{~km}$ altitude. The observed electron temperature anisotropy is attributed to the large ambipolar electric field that is required to maintain quasi-neutrality along the field line in the presence of escaping atmospheric photoelectrons, and to the Coulomb collisions between the low-energy ambient electrons and the more energetic photoelectrons (Yau et al., 1995). The heat flux carried by 


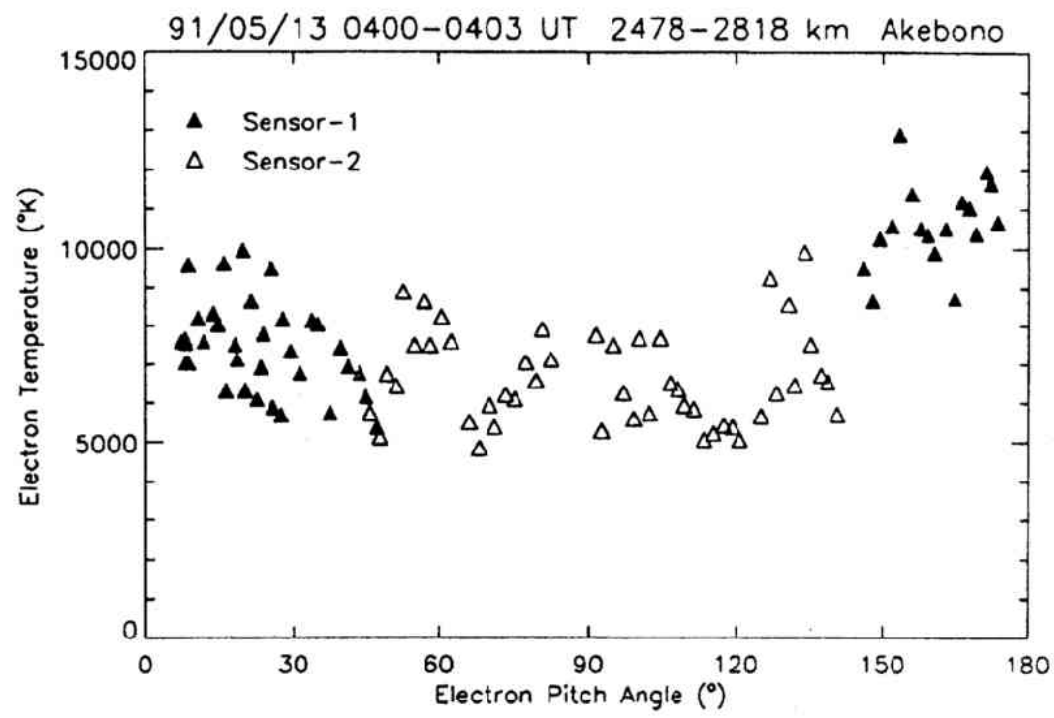

Fig. 4. Measured TED polar wind electron temperature as a function of pitch angle in a low-altitude, northern polar-cap Akebono orbit pass.

the $>10-\mathrm{eV}$ atmospheric photoelectrons observed by LEP is upward and typically about $2 \times 10^{-6}$ Joule $\mathrm{m}^{-2} \mathrm{~s}^{-1}$. The actual photoelectron heat flux including the $<10-\mathrm{eV}$ component of photoelectrons is probably somewhat larger, and comparable in magnitude to the upward thermal-energy electron heat flux. In comparison, the predicted heat flux in polar wind models (e.g., Schunk and Watkins, 1981) is typically downward and 1 to 2 orders of magnitude smaller. In other words, the upward heat flux due to the observed electron temperature anisotropy dominates any downward heat flux due to electron temperature gradients that may be present in the polar wind plasma.

\section{Suprathermal Auroral Ions}

On Akebono, the SMS and LEP instruments frequently observe "ion conics" above $3000 \mathrm{~km}$ in the auroral ionosphere (Whalen et al., 1991; Miyake et al., 1993). These are upflowing ionospheric ions(UFI) in the suprathermal $(0.01-1 \mathrm{keV})$ and energetic $(>\mathrm{keV})$ energy ranges in which the ion flux peaks at a pitch angle away from the field line in the upward direction. They are believed to be transversely energized or accelerated ions (TEI or TAI) originating from a loweraltitude, i.e., ions which are energized perpendicular to the local magnetic field and then mirror up the divergent magnetic field.

There exist a number of detailed or statistical studies of auroral ion conics based on earlier ISIS-1, ISIS-2, S3-3, DE-1, and Viking data (Klumpar, 1979; Gorney et al., 1981; Yau et al., 1985; Thelin et al., 1990; Peterson et al., 1992). However, few of these earlier studies refer to observations in the transverse energization region itself (Kintner et al., 1984; Peterson et al., 1988), and none contains a complete characterization of the ion population in both the thermal and the suprathermal energy ranges in and near the source region.

In contrast, Akebono frequently encounters regions of transverse ion energization in the 3000-6000 $\mathrm{km}$ altitude region both on the dayside and the nightside (Whalen et al., 1991), in which the observed suprathermal ions are peaked at $90^{\circ}$ pitch angles. The spatial (latitudinal) extent of the energization region is often $100 \mathrm{~km}$ or less. In the region, all ions (major and minor species) are energized to approximately the same energy (temperature) perpendicular to the magnetic field. Immediately below the region (on adjacent field lines), the plasma is characterized by lower density, a downward directed density gradient, 
and upward (bulk) flow of all major ions. Within a few thousand kilometers above the region, significant variations from conservation of the first invariant are observable in the "conic" distributions.

On the dayside at high altitude, the observed ion conic distributions often appear at a sharp equatorward boundary of the cusp/cleft region with a $\sim 90^{\circ}$ pitch angle peak, and extend to higher latitudes at increasingly larger pitch angles (in the northern hemisphere). The degree of folding of the distribution toward the upward magnetic field direction varies inversely with the ion mass. Figure 5 shows the peak pitch angles of the measured suprathermal $(\sim 150 \mathrm{eV}) \mathrm{H}^{+}, \mathrm{He}^{+}$, and $\mathrm{O}^{+}$ions in an observed heating (energization) event, as a function of time after the encounter of the heating region. The northward component of the satellite velocity was $\sim 1 \mathrm{~km} / \mathrm{s}$. Therefore, the plot covers roughly $150 \mathrm{~km}$ in latitudinal extent. The pitch angles show a clear increase with latitude and decrease with ion mass.

Knudsen et al. (1994) showed that the latitude and ion mass variations of the observed conic pitch angles in this figure can be well explained by a model of a narrow, wall-like polar cusp heating region extending in longitude and in altitude from $2000 \mathrm{~km}$ up to the satellite altitude $(8000 \mathrm{~km})$, through which the ions convect northward. The solid lines in the figure show the fitted pitch angles from their model, in which a fraction of the cold $\mathrm{H}^{+}, \mathrm{He}^{+}$and $\mathrm{O}^{+}$ions become energized to $150 \mathrm{eV}$ instantaneously as they convect through the region, and the energized ions are subject to convection and the gradient- $\mathrm{B}$ force. Knudsen et al. (1994) found consistently good agreement between the fitted and measured pitch angles for suprathermal ions. For thermal-energy ions, however, a discrepancy between the two exists, in that the observed pitch angles are similar to those of suprathermal ions while the model predicts smaller pitch angles.

From the measured ion energy (RPA) spectra inside and immediately poleward of the heating region, relative to those immediately equatorward of it, and from the northward ion convection velocity, the heating time in the plasma frame is estimated to be $\sim 20 \mathrm{~s}$; the width of the heating region is $\sim 30 \mathrm{~km}$ in northsouth extent, and the core ion heating rate is on the order of a few eV/s.

Miyake et al. (1993) found that the average energy of the ion conics observed by LEP on the dayside increases with altitude between 3000 and $9000 \mathrm{~km}$. Figure 6 is a scatter plot of the apex angle and temperature of the observed conics versus altitude. The curves in Fig. 6(a) represent the expected

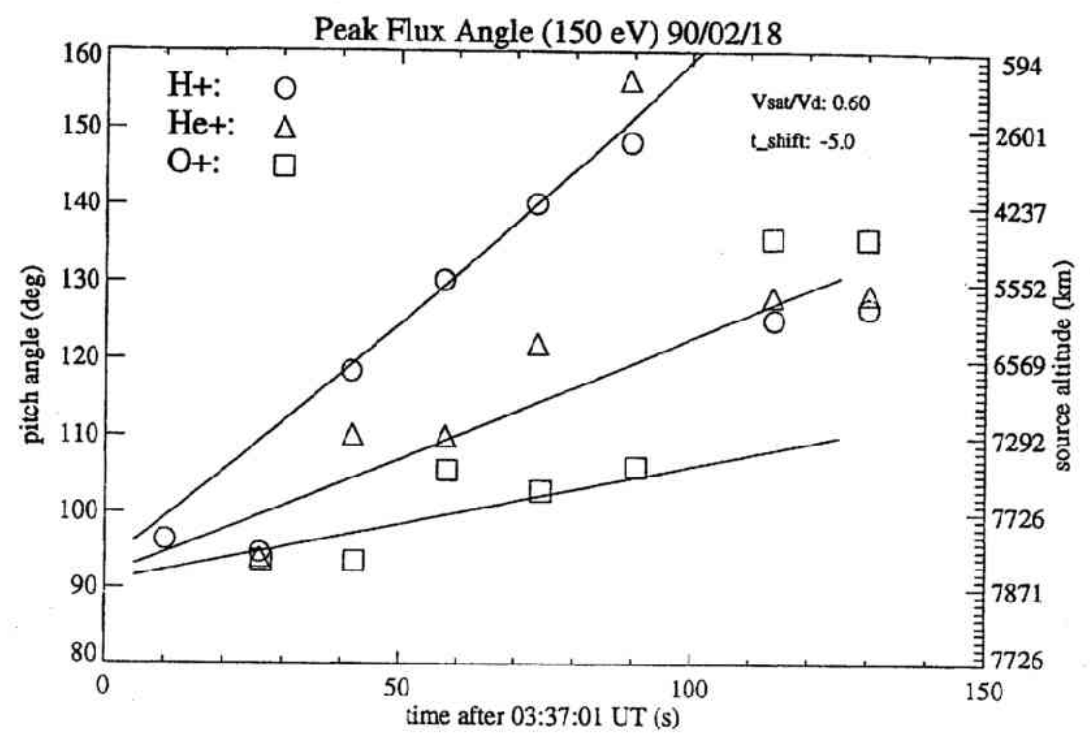

Fig. 5. Measured (symbols) and fitted (curves) peak pitch angles of energized $(\sim 150 \mathrm{eV}) \mathrm{H}^{+}, \mathrm{He}^{+}$, and $\mathrm{O}^{+}$ions inside and immediately (within $\sim 150 \mathrm{~km}$ ) poleward of a transverse ion energization region on the dayside, as a function of time after the encounter with the region, showing the increase of the pitch angle with latitude and its decrease with ion mass; see text. 
variations of the apex angle with altitude due to transverse energization followed by magnetic mirroring and conservation of adiabatic invariant. The apex angle of the observed conics decreases with increasing altitude much more slowly than expected from conservation of adiabatic invariant. The temperature of the conics, which is derived from the measured ion velocity phase space distribution in the $30-10^{4} \mathrm{eV}$ ion energy range, increases from $\sim 10 \mathrm{eV}$ near $2000 \mathrm{~km}$, to $\leq 100 \mathrm{eV}$ near $9000 \mathrm{~km}$. Note that the increase in averaged energy with altitude does not necessarily imply that the observed ions at high altitude have been energized over an extended altitude range below the satellite. Indeed, Miyake et al. (1993) excluded the extended (bimodal) conics in their analysis. As shown earlier, the observed energy and angular distributions of the ion conics (at a particular point of the orbit) on the dayside can be well explained in terms of the ions being transversely energized over a narrow latitudinal and altitudinal extent at a lower altitude as they convect across the energization region. Note also that the process of transverse ion energization can occur in localized altitudinal regions over a wide range of altitudes. Peterson et al. (1993) have presented simultaneous Akebono and DE-1 observations at two different altitudes on (nearly) the same field line in the dayside cusp, which are indicative of the simultaneous occurrence of ion acceleration at two widely separated altitudes on a field line. Yau et al. (1983) observed transversely energized ions up to $500 \mathrm{eV}$ on sounding rockets down to $400 \mathrm{~km}$ altitude during active aurora.

During extended periods of auroral activity, SMS occasionally observes upflowing molecular ions $\left(\mathrm{NO}^{+}\right.$and $\mathrm{N}_{2}^{+}$) in the high-altitude auroral zone both in the dayside and the nightside (Yau et al., 1993).

(a)

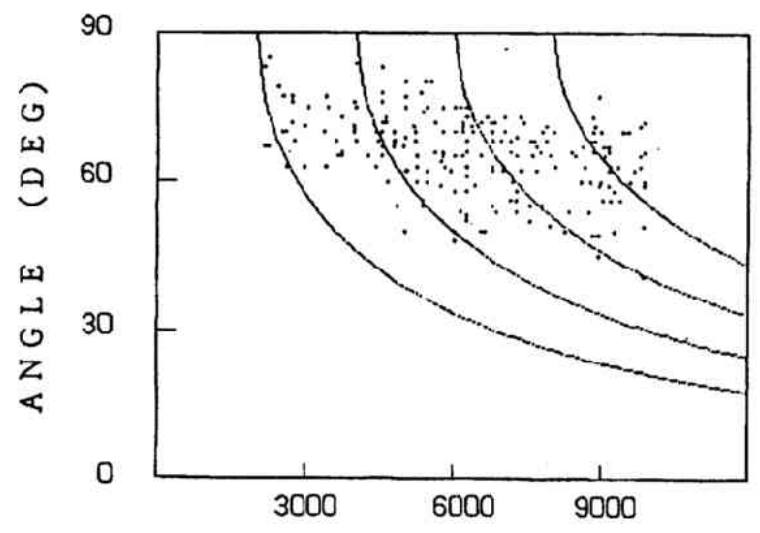

(b)

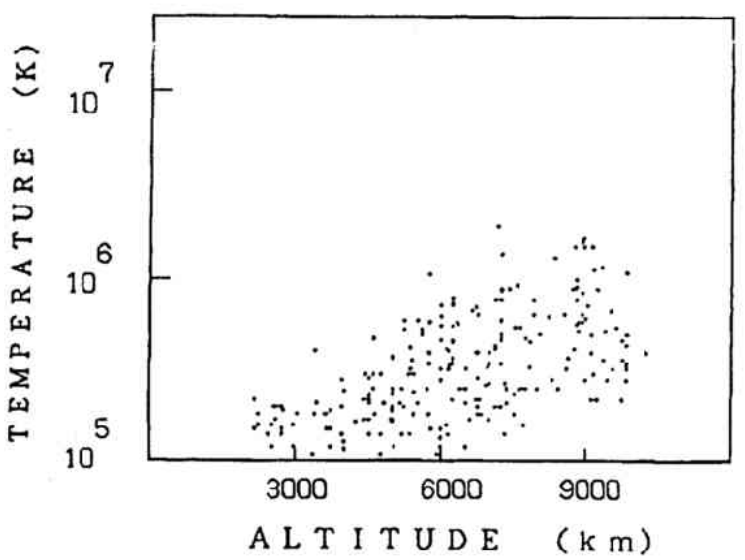

Fig. 6. Scatter plots of (a) pitch angle and (b) temperature of ion conics in the dayside auroral zone observed by Akebono LEP as a function of altitude. 


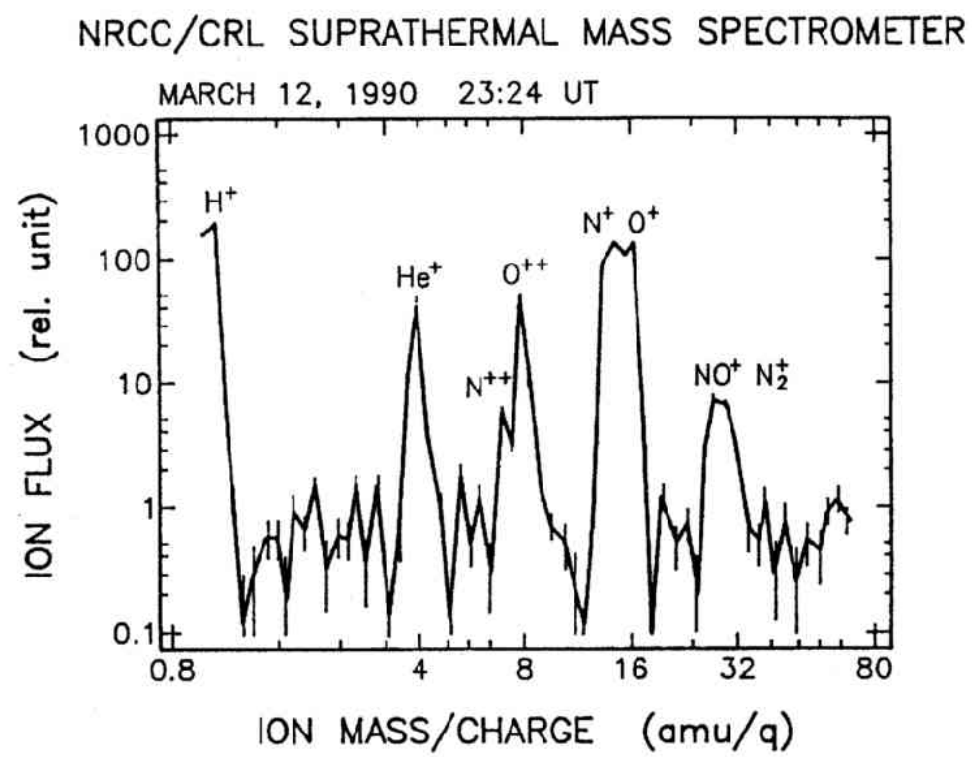

Fig. 7. SMS ion mass spectrum of observed upflowing ions in the dayside auroral zone near Akebono apogee $\left(76^{\circ} \Lambda, \sim 10 \mathrm{MLT}\right.$, $9000 \mathrm{~km}$ altitude) during the main phase of a large magnetic storm, showing the presence of comparable fluxes of $\mathrm{H}^{+}, \mathrm{N}^{+}$ and $\mathrm{O}^{+}$ions and smaller fluxes of molecular $\mathrm{N}_{2}^{+}$and $\mathrm{NO}^{+}$ions in addition to $\mathrm{He}^{+}$and $\mathrm{O}^{++}$ions.

At Akebono altitudes, these ions appear to be nearly field-aligned, and have energies higher than $10 \mathrm{eV}$. Figure 7 shows a mass spectrum of the observed upflowing ions in the dayside auroral zone near Akebono apogee $\left(76^{\circ} \Lambda, \sim 10 \mathrm{MLT}, 9000 \mathrm{~km}\right.$ altitude) during the main phase of a large magnetic storm. Intense fluxes of low-energy, upward, field-aligned ions were present at 1, 4, 8, 14-16, and 28-30 amu/q in the spectrum. The fluxes at 1 and 14-16 amu/q are comparable, and are about a decade larger than those in other masses. Detailed mass spectral analysis indicates the presence of comparable fluxes of $\mathrm{H}^{+}, \mathrm{N}^{+}$, and $\mathrm{O}^{+}$, and smaller fluxes of $\mathrm{N}_{2}^{+}$, and $\mathrm{NO}^{+}$, in addition to $\mathrm{He}^{+}$and $\mathrm{O}^{++}$.

Peterson et al. (1994) analyzed the extensive complement of plasma, field, and wave data on Akebono in a number of upflowing molecular ion events in the nightside auroral ionosphere (above 5000 $\mathrm{km})$. They showed that the observed ions must acquire an energy of the order of $10 \mathrm{eV}$ at ionospheric $(F$ region) altitudes, in a time short compared with the local dissociative recombination time of the ions, which is of the order of minutes. Their analysis shows that neither Joule heating nor ion resonance heating transfers enough energy or transfers the energy fast enough to account for the observed fluxes of upflowing molecular ions, and points to the likely existence of an as yet unidentified, fast ion energization process at. the $F$-region or topside ionosphere.

\section{Discussion}

In summary, the Akebono observations of the polar wind have revealed a number of important new features: (1) the polar wind $\mathrm{H}^{+}$ion acceleration is largest at $2000-4000 \mathrm{~km}$ altitude; (2) the velocity of heavy $\left(\mathrm{O}^{+}\right)$ions is significant at high altitudes; (3) the ion velocity correlates with the electron temperature, indicative of ambipolar electric field; (4) the thermal electron temperature in the upward magnetic field direction is higher than that in the perpendicular and downward directions; (5) this results in a significant heat flux in the upward direction, which dominates any downward heat flux that may be present; (6) the polar wind flux in the high-altitude polar cap is not uniform, in that ion depletion zones are frequently present in the nightside polar cap. 
The suprathermal ion observation on Akebono reveals the frequent occurrence of transverse ion energization in the mid-altitude auroral zone. It also demonstrates very clearly the localized nature of the energization, both in altitude and in latitude. In addition, it confirms the occurrence of multiple ion energization along the magnetic field line, and points to the likely existence of a fast ion energization process at ionospheric altitude, for the initial energization of heavy ions during active aurora.

We thank our many colleagues on the Akebono Science Team for their co-operations, and the Canadian Space Agency for support of the Akebono Suprathermal Mass Spectrometer (SMS) Experiment.

\section{REFERENCES}

Abe, T., K. I. Oyama, H. Amemiya, S. Watanabe, T. Okuzawa, and K. Schlegel, Measurements of temperature and velocity distribution of thermal electrons by the Akebono (EXOS-D) satellite: Experimental setup and preliminary results, J. Geomag. Geoelectr., 42, 537-554, 1990.

Abe, T., B. A. Whalen, A. W. Yau, R. E. Horita, S. Watanabe, and E. Sagawa, EXOS D (Akebono) Suprathermal Mass Spectrometer observations of the polar wind, J. Geophys. Res., 98, 11191-11203, 1993a.

Abe, T., B. A. Whalen, A. W. Yau, S. Watanabe, E. Sagawa, and K. I. Oyama, Altitude profile of the polar wind velocity and its relationship to ionospheric conditions, Geophys. Res. Lett., 20, 2825-2828, 1993b.

Abe, T., S. Watanabe, B. A. Whalen, A. W. Yau, and E. Sagawa, Observations of polarwind and thermal ion outflow by Akebono/ SMS, J. Geomag. Geoelectr., 1995 (to be submitted).

Banks, P. M. and T. E. Holzer, The polar wind, J. Geophys. Res., 73, 6846-6854, 1968.

Barakat, A. R. and R. W. Schunk, O+ ${ }^{+}$ions in the polar wind, J. Geophys. Res., 88, 7887-7894, 1983.

Chandler, M. O., J. H. Waite, Jr., and T. E. Moore, Observations of polar ion outflows, J. Geophys. Res., 96, 1421-1428, 1991.

Chappell, C. R., The terrestrial plasma source: a new perspective in solar terrestrial processes from Dynamics Explorer, Rev. Geophys., 26, 229-248, 1988.

Dessler, A. J. and F. C. Michel, Plasma in the geomagnetic tail, J. Geophys. Res., 71, 1421-1428, 1966.

Gombosi, T. I. and A. F. Nagy, Time-dependent modeling of field-aligned current-generated ion transients in the polar wind, J. Geophys. Res., 94, 359-369, 1989.

Gombosi, T. I., T. E. Cravens, and A. F. Nagy, A time-independent theoretical model of the polar wind: preliminary results, Geophys. Res. Lett., 12, 167-170, 1985.

Gorney, D. J., A. Clarke, D. Croley, J. F. Fennell, J. Luhmann, and P. F. Mizera, The distribution of ion beams and conics below 8000 km, J. Geophys. Res., 86, 83-89, 1981.

Ho, C. W., J. L. Horwitz, N. Singh, G. R. Wilson, and T. E. Moore, Effects of magnetospheric electrons on polar plasma flow: a semikinetic model, J. Geophys. Res., 97, 8425-8437, 1992.

Ho, C. W., J. L. Horwitz, and T. E. Moore, DE-1 observations of polar $\mathrm{O}^{+}$stream bulk parameters and composition with a model of the centrifugally accelerated polar wind, Geophys. Res. Lett., 21, 2459-2462, 1994.

Hoffman, J. II. and W. II. Dodson, Light ion concentrations and fluxes in the polar regions during magnetically quiet times, $J$. Geophys. Res., 85, 626-632, 1980.

Holzer, T. E., J. A. Fedder, and P. M. Banks, A comparison of kinetic and hydrodynamic models of an expanding ion exosphere, J. Geophys. Res., 76, 2453-2468, 1971.

Horita, R. E., A. W. Yau, B. A. Whalen, T. Abe, and S. Watanabe, Ion depletion zones in the polar wind: EXOS D Suprathermal Ion Mass Spectrometer observations in the polar cap, J. Geophys. Res., 98, 11,439-11,448, 1993.

Horwitz, J. L., C. W. Ho, H. D. Scarbro, G. R. Wilson, and T. E. Moore, Centrifugal acceleration of the polar wind, J. Geophys. Res., 99, 15051-15064, 1994.

Kintner, P. M. and D. J. Gorney, A search for the plasma processes associated with perpendicular ion heating, J. Geophys. Res., 89, 937-944, 1984.

Klumpar, D. M., Transversely accelerated ions: an ionospheric source of hot magnetospheric ions, J. Geophys. Res., 84, 4229$4237,1979$.

Knudsen, D. J., B. A. Whalen, T. Abe, and A. W. Yau, Temporal evolution and spatial dispersion of ion conics: Evidence for a polar cusp heating wall, in Solar System Plasmas in Space and Time, Geophys. Monogr. Ser., Vol. 84, edited by J. L. Burch and W. H. Waite, Jr., pp. 163-169, AGU, Washington, D.C., 1994.

Lemaire, J., $\mathrm{O}^{+}, \mathrm{H}^{+}$, and $\mathrm{He}^{+}$ion distributions in a new polar wind model, J. Atmos. Terr. Phys., 34, 1647-1658, 1972.

Lockwood, M., J. H. Waite, Jr., T. E. Moore, J. F. E. Johnson, and C. R. Chappell, A new source of suprathermal $\mathrm{O}^{+}$ions near the dayside polar cap boundary, J. Geophys. Res., 90, 4099-4116, 1985.

Marubashi, K., Escape of the polar-ionospheric plasma into the magnetospheric tail, Rep. Iono. Space Res. Jpn., 24, 322-346, 1970.

Mitchell, H. G. and P. J. Palmadesso, A dynamic model for the auroral ficld line plasma in the presence of field-aligned current, J. Geophys. Res., 88, 2131-2139, 1983. 
Miyake, W., T. Mukai, and N. Kaya, On the evolution of ion conics along the field line from EXOS-D observations, J. Geophys. Res., 98, 11,127-11,134, 1993.

Mukai, T., N. Kaya, E. Sagawa, M. Hirahara, W. Miyake, T. Obara, H. Miyaoka, S. Machida, H. Yamagishi, M. Ejiri, H. Matsumoto, and T. Itoh, Low energy charged particle observations in the "auroral" magnetosphere: First results from the Akebono (EXOS-D) satellite, J. Geomag. Geoelectr., 42, 479-496, 1990.

Nagai, T., J. H. Waite, J. L. Green, C. R. Chappell, R. C. Olsen, and R. H. Comfort, First measurements of supersonic polar wind in the polar magnetosphere, Geophys. Res. Lett., 11, 669-672, 1984.

Nishida, $\Lambda$., Formation of plasmapause, or the magnetospheric plasma knee, by the combined action of magnetospheric convection and plasma escape from the tail, J. Geophys. Res., 71, 5669-5679, 1966.

Peterson, W. K., E. G. Shelley, S. A. Boardsen, D. A. Gurnett, B. G. Ledley, M. Suguira, T. E. Moore, and J. H. Waite, Transverse ion energization and low-frequency plasma waves in the mid-altitude auroral zone: A case study, J. Geophys. Res., 93, 11,40511,428, 1988.

Peterson, W. K., H. L. Collin, M. F. Doherty, and C. M. Bjorkland, $\mathrm{O}^{+}$and $\mathrm{He}^{+}$restricted and extended (bimodal) ion conic distributions, Geophys. Res. Lett., 19, 1439-1442, 1992.

Peterson, W. K., A. W. Yau, and B. A. Whalen, Simultaneous observations of $\mathrm{H}^{+}$and $\mathrm{O}^{+}$ions at two altitudes by the Akebono and Dynamics Explorer-1 satellites, J. Geophys. Res., 98, 11,177-11,190, 1993.

Peterson, W. K, T. Abe, H. Fukunishi, M. J. Greffen, H. Hayakawa, Y. Kasahara, I. Kimura, A. Matsuoka, T. Mukai, T. Nagatsuma, K. Tsuruda, B. A. Whalen, and A. W. Yau, On the sources of energization of molecular ions at ionospheric altitudes, J. Geophys. Res., 99, 23257-23274, 1994.

Pollock, C. J., M. O. Chandler, T. E. Moore, J. H. Waite, Jr., C. R. Chappell, and D. A. Gurnett, A survey of upwelling ion event characteristics, J. Geophys. Res., 95, 18969-18980, 1990.

Schunk, R. W. and J. J. Sojka, A three-dimensional time-dependent model of the polar wind, J. Geophys. Res., 94, 8973-8991, 1989.

Schunk, R. W. and D. S. Watkins, Electron temperature anisotropy in the polar wind, J. Geophys. Res., 86, 91-102, 1981.

Thelin, B., B. Aparicio, and R. Lundin, Observations of upflowing ionospheric ions in the mid-altitude cusp/cleft region with the Viking satellite, J. Geophys. Res., 95, 5931-5939, 1990.

Tsuruda, K. and H. Oya, Introduction to the Exos-D (Akebono) project, Geophys. Res. Lett., 18, 293-295, 1991.

Watanabe, S., B. A. Whalen, and A. W. Yau, Thermal ion observations of depletion and refilling in the plasmaspheric trough, J. Geophys. Res., 97, 1081-1096, 1992.

Whalen, B. A., J. R. Burrows, A. W. Yau, E. E. Budzinski, A. M. Pilon, I. Iwamoto, K. Marubashi, S. Watanabe, H. Mori, and E. Sagawa, The suprathermal ion mass spectrometer (SMS) for the Akebono (EXOS-D) spacecraft, J. Geomag. Geoelectr., 42, 511-536, 1990.

Whalen, B. A., S. Watanabe, and A. W. Yau, Thermal and suprathermal ion observations in the low altitude transverse ion energization region, Geophys. Res. Lett., 18, 725-728, 1991.

Yau, A. W. and M. Lockwood, Vertical ion outflow in the polar ionosphere, in Magnetosphere Ionosphere Plasma Models, Geophys. Monogr. Ser., Vol. 44, edited by T. E. Moore and J. H. Waite, Jr., pp. 229-240, AGU, Washington, D.C., 1988.

Yau, A. W., B. A. Whalen, A. G. McNamara, P. J. Kellogg, and W. Bernstein, Particle and wave observations of low-altitude ionospheric ion acceleration events, J. Geophys. Res., 88, 341-355, 1983.

Yau, A. W., E. G. Shelley, W. K. Peterson, and L. Lenchyshyn, Energetic auroral and polar ion outflow at DE 1 altitudes: Magnitude, composition, magnetic activity dependence, and long-term variations, J. Geophys. Res., 90, 8417-8432, 1985.

Yau, A. W., B. A. Whalen, and E. Sagawa, Minor ion composition in the polar ionosphere, Geophys. Res. Lett., 18, 345-348, 1991.

Yau, A. W., B. A. Whalen, C. Goodenough, E. Sagawa, and T. Mukai, EXOS-D (Akebono) observations of molecular NO ${ }^{+}$and $\mathrm{N}_{2}{ }^{+}$upflowing ions in the high-altitude auroral ionosphere, J. Geophys. Res., 98, 11205-11224, 1993.

Yau, A. W., B. A. Whalen, T. Abe, T. Mukai, K. I. Oyama, and T. Chang, Akebono observations of electron temperature anisotropy in the polar wind, J. Geophys. Res., 100, 17451-17463, 1995. 